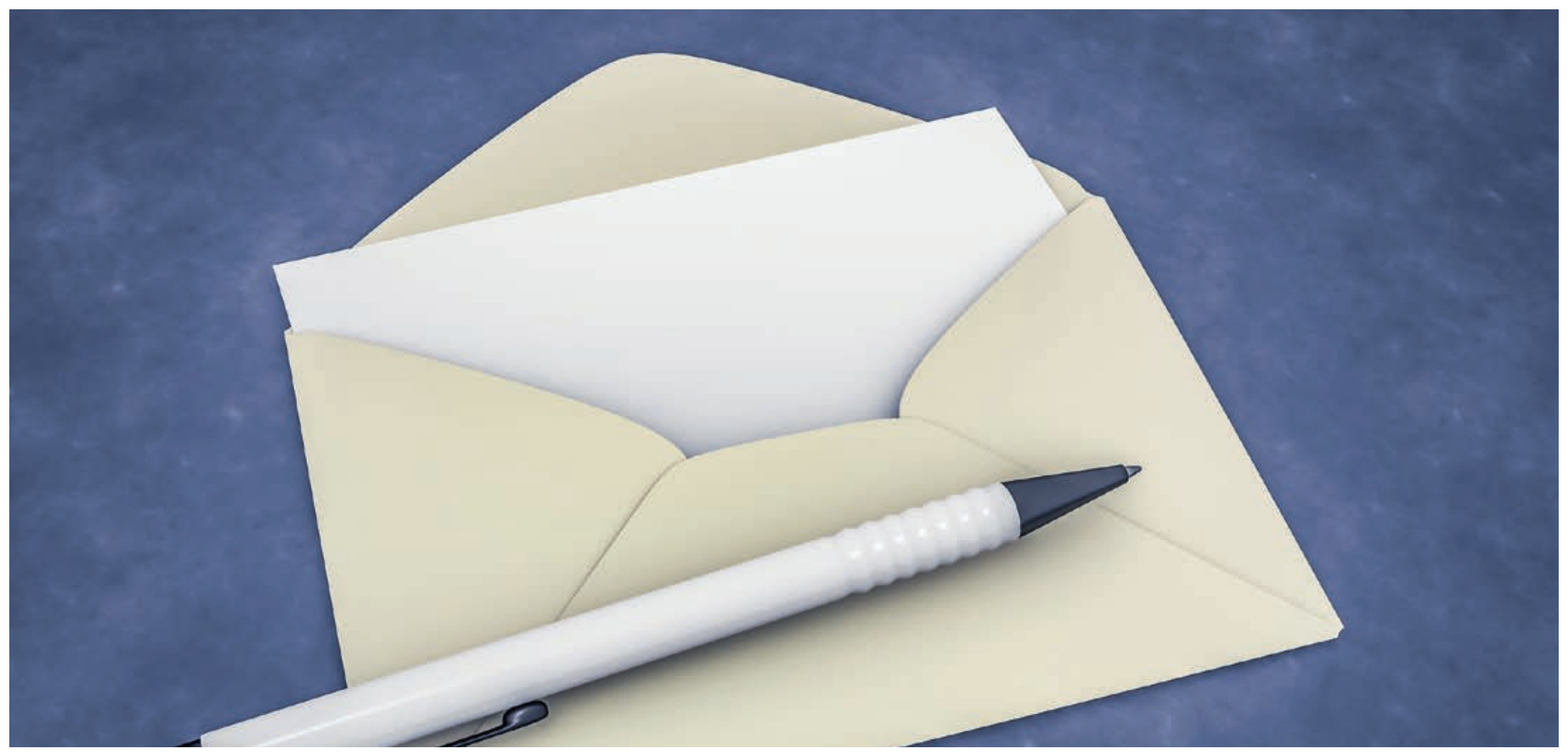

\title{
Lettre ouverte aux présidents des sociétés de médecine
}

\section{Pierre Gachoud}

Spécialiste en médecine générale, membre FMH

Mesdames, Messieurs,

chers Confrères et chères Consœurs,

Les revenus des médecins, objet de débats passionnés dans les médias, ont fait couler beaucoup d'encre. Permettez à un médecin de premier recours de s'exprimer, après 45 ans d'expérience hospitalière et privée, en observateur attentif de la politique médicale!

J'ai tenté depuis 30 ans à plusieurs reprises, d'intervenir dans les assemblées de la Société de Médecine du Canton de Fribourg, lorsqu'il s'agissait de remanier les tarifs médicaux.

La première fois, j'ai pris la parole pour m'opposer à la votation d'une augmentation de certains actes gynécologiques, argumentant que mes confrères gynécologues avaient un revenu moyen 4 fois plus élevé que les médecins de premier recours de la ville, pourtant tout aussi autant sollicités par des urgences et des services de garde. Mon intervention, appuyée par les pédiatres en particulier, n'a rien changé dans les faits, et les gynécologues ayant obtenu facilement l'augmentation demandée.

Lors des prénégociations TARMED à Berne, mandaté par le groupe fribourgeois des généralistes, j’ai avancé les mêmes arguments, un tableau des revenus des médecins selon leur spécialité à l'appui. Non contents de m'empêcher de projeter le tableau recensant des revenus de 90000 à 900000 francs imposables annuellement pour un plein temps par ordre croissant: pédiatre, interniste, généraliste, chirurgien général, ORL, ophtalmologue, urologue et gynécologue, plusieurs spécialistes m’ont également admonesté, disant qu'ils n'avaient pas accompli une si longue formation pour le salaire d'un «simple généraliste» (sic!)

Ils avaient obtenu leur titre FMH en 6 ans, alors que j'avais pour ma part, comme généraliste, 8 ans et demi de formation! Entre nous, s.v.p., qui croit qu'il faut être 
exceptionnel pour devenir radiologue, urologue ou ophtalmologue?

Lors de l'adoption de TARMED, plusieurs sociétés de spécialistes ont menacé de quitter le FMH et de refuser les négociations avec les assureurs maladie. Le président de la FMH a même été menacé de violences physiques! Est-ce tolérable?

Par crainte de faire éclater la FMH et de mettre en péril la cohésion de la corporation, par crainte aussi de donner à l'opinion publique une image aussi désastreuse des médecins, le TARMED en est sorti finalement au bénéfice de la plupart des spécialistes, si bien que rien n'a changé sur le fond.

Or rappelons que l'idée était de rémunérer de façon à peu près égale tous les médecins à une moyenne horaire d'environ 200 francs, tous ayant le même nombre d'années d'études et de formation postgraduée, et les mêmes responsabilités. En effet, le pédiatre, au bas de l'échelle des rémunérations, travaille aussi 60 heures par semaine et sauve des vies en réanimant des nouveau-nés ou décelant à temps la méningite ou la pneumonie fatale!

Faire croire que l'excellence et une responsabilité accrue permettent une tarification supplémentaire est un vrai mythe. L'excellence, le cas échéant, pourrait justifier 50\% d'honoraires en plus, mais pas $1000 \%$.

On ne peut plus tolérer les abus dans un système de cumulation des actes techniques aboutissant, dans les extrêmes, à des revenus variant de 1 à 10 pour un travail de médecin à plein temps. On ne peut plus tolérer, en droit, que $10 \%$ de nos confrères vous menacent de sécession, vous les sociétés cantonales et la FMH, ternissant notre profession, interprétant le tarif en leur faveur, confondant leur vraie valeur avec leur revenu, "pourrissant» les séances de nos sociétés professionnelles de leurs velléités. Pourquoi donc, vous les pré- sidents et le comité des dites sociétés, déployez-vous autant d'énergie à défendre leur comportement incivil? Dans vos réponses aux médias, vous refusez d'admettre qu'il y a des abus, répétant, sur la défensive, que les coûts de la santé ne sont pas dus aux médecins, mais aux politiciens, aux assureurs, aux patients... Pourtant nous sommes bien l'un des acteurs-clé et donc coresponsables des dépenses, et, en matière de rationalisation, nous devons tous nous y mettre!

Nos confrères les plus extrêmes ne devraient-ils pas être plutôt sanctionnés par les commissions d'éthique et non absouts par un silence assourdissant?

Il serait temps que vous ne vous laissiez plus intimider par les menaces de ceux qui sont éblouis par le confort matériel, dénués de l'esprit de partage, favorisés par un système inéquitable, et que vous soyez davantage à l'écoute des confrères défavorisés, n’ayant ni radiologie, ni laboratoire, ni actes techniques surévalués pour faire du «chiffre».

"Malheureusement», les médecins de premier recours ne font pas de tapage, ils ne revendiquent pas, ne menacent pas, inoffensifs qu'ils sont pour nos instances faîtières.

Ils sont pourtant la fierté et l'honneur de notre profession dans l'humilité et le sens du devoir selon le serment d'Hippocrate (qui n'est, hélas, plus lu lors des intronisations dans les sociétés de médecine!)

Veuillez agréer, Mesdames et Messieurs les Présidents, chers Confrères, chers Consœurs, le témoignage de notre gratitude pour votre disponibilité, votre sens du Service qui pourrait être un exemple pour tous ceux qui en ont un urgent besoin.

\section{Crédit photo}

(c) Magann | Dreamstime.com 